\title{
Convective Heat Transfer Model through Annular Finned Evaporator of a Cold Storage Using Taguchi Regression, $\mathbf{S} / \mathbf{N}$ Ratio and ANOVA Analysis
}

\author{
*Dr. N. Mukhopadhyay, **Tapan Mondal \\ *Assistant Professor, Department of Mechanical Engineering, Jalpaiguri Government Engineering College, \\ Jalpaiguri-735102, West Bengal, India \\ ** Post Graduate scholar, Department of Mechanical Engineering, Jalpaiguri Government Engineering \\ College, Jalpaiguri-735102, West Bengal, India
}

\begin{abstract}
To overcome the energy crisis and increase of cost of electrical energy to operate the cold storage various design of experiments are done to optimize different control factors of a cold storage evaporator space inside the cold room. Here we have use annular fin to maximize the heat absorption by evaporator. Taguchi orthogonal array with regression analysis have been used as a design of experiments. The control factors are Area of the evaporator with annular fin(A), temperature difference of the evaporator space (dT), and relative humidity inside the cold $\operatorname{room}(\mathrm{RH})$. The Taguchi $\mathrm{S} / \mathrm{N}$ ratio analysis have used as an optimization technique. Larger the better type $\mathrm{S} / \mathrm{N}$ ratio have used for calculating the optimum level of control parameters, because it is a maximization problem. Analysis of variance ANOVA was also performed on the test results to find out the significant control factors.

Key Words: Taguchi orthogonal array, convective heat transfer co-efficient, annular fin area and arrangement, regression analysis, graphical representation of control factors with heat transfer, $\mathrm{S} / \mathrm{N}$ ratio analysis, ANOVA analysis.
\end{abstract}

\section{INTRODUCTION}

Cold storages form the most important element for proper storage and distribution of vide variety of perishables like fruits, vegetables and fish or meat processing. India is the largest producer of fruits and second largest producer of vegetables in the world. In spite of that per capita availability of fruits and vegetables is quite low because of post harvest losses that account for about 25 to $30 \%$ of production. Besides, quality of a sizable quantity of products also deteriorates by the time it reaches the consumer. As India is the second largest producer $(45,343,600$ tonnes at 2015) of potato after China and largest producer of the ginger (702000 metric tonnes i.e. $34.6 \%$ of the world total) without these there are many kind of food commodities are produce in our country so demand for cold storages have been increasing rapidly over the past couple of decades so that food commodities can be uniformly supplied all through the year and food items are prevented from perishing. Besides the role of stabilizing market prices and evenly distributing both on demand basis and time basis, the cold storage industry provide other advantages and benefits to both the farmers and the consumers. The farmers get the opportunity to get a good return of their hard work. On the consumer sides they get the perishable commodities with lower fluctuation of price. Very little theoretical and experimental studies are being reported in the journal on the performance enhancement of cold storage. Energy crisis is one of the most important problems the world is facing nowadays. With the increase of cost of electrical energy operating cost of cold storage storing is increasing which forces the increased cost price of the commodities that are kept. So it is very important to make cold storage energy efficient or in the other words reduce its energy consumption. Thus the storage cost will eventually come down. In case of conduction we have to minimize the leakage of heat through wall but in convection maximum heat should be absorbed by refrigerant to create cooling uniformity thought out the evaporator space. If the desirable heat is not absorbed by tube or pipe refrigerant then temp of the refrigerated space will be increased, which not only hamper the quality of the product which has been stored there but reduces the overall performance of the plant. That's why a mathematical modelling is absolutely necessary to predict the performance. In this paper we have proposed a theoretical heat transfer model of convective heat transfer model development of a cold storage using Taguchi L9 orthogonal array. Area of the evaporator with fin (A), Temperature difference (dT), Relative Humidity $(\mathrm{RH})$ are the basic variables and three ranges are taken each of them in the model development. A graphical interpretation from the model justifies the reality. 


\section{MODEL DEVELOPMENT}

\section{Range and Parameter Selection}

The length, breath and heightof each chamber of cold storage are $60 \mathrm{~m}, 30 \mathrm{~m}$ and $15 \mathrm{~m}$ respectively.

The three values of area of the evaporator with fin (A) of evaporator space are $0.5407 \mathrm{~m}^{2}, 0.6508 \mathrm{~m}^{2}$ and
$0.8204 \mathrm{~m}^{2}$ respectively. The three values of temperature difference $(\mathrm{dT})$ of evaporator space are $2,5 \& 8$ centigrade respectively. The three values of relative humidity $(\mathrm{RH})$ of evaporative space are 0.85 , $0.90 \& 0.95$ respectively.

Table no. 1 Control factors with their range

\begin{tabular}{|c|c|c|c|c|c|}
\hline \multirow{2}{*}{ Notation } & Factors & \multirow{2}{*}{ Unit } & \multicolumn{3}{|c|}{ Levels } \\
\cline { 4 - 6 } $\mathrm{A}$ & $\begin{array}{c}\text { Area of the } \\
\text { evaporator } \\
\text { with fin }\end{array}$ & $\mathrm{m}^{2}$ & 0.5407 & 0.6508 & 0.8204 \\
\hline $\mathrm{dT}$ & $\begin{array}{c}\text { Temperature } \\
\text { Difference }\end{array}$ & ${ }^{\circ} \mathrm{C}$ & 2 & 5 & 8 \\
\hline $\mathrm{RH}$ & $\begin{array}{c}\text { Relative } \\
\text { Humidity }\end{array}$ & $\%$ & 0.85 & 0.90 & 0.95 \\
\hline
\end{tabular}

In this study, Mohitnagar cold storage (Jalpaiguri) \& Teesta cold storage has been taken as a model of observation.

\section{Regression Analysis}

Regression analysis is the relationship between various variables. Using regression analysis one can construct a relationship between response variable and predictor variable. It demonstrates what will be the changes in response variable because of change in predictor variable. Simple regression equation is,

$$
\mathrm{y}=\mathrm{a}+\mathrm{b} \mathrm{x}
$$

In this problem more than one predictor variable is involved and hence simple regression analysis cannot be used. We have to take the help of multiple regression analysis. There are two types of multiple regression analysis- i) Simple multiple regression analysis (regression equation of first order) ii) Polynomial multiple regression analysis (regression equation of second order or more). Simple multiple regression analysis is represented by the equation of first order regression

$Y=\beta_{0}+\beta_{1} X_{1}+\beta_{2} X_{2}+\beta_{3} X_{3}+\ldots \ldots \ldots \ldots \ldots \ldots . .+\varepsilon$

Where $\beta$ is constant terms $\& \mathrm{X}$ is the variables $\& \varepsilon$ is the experimental error.
Polynomial multiple regression analysis equation is $\mathrm{Y}=\beta_{0}+\beta_{1} \mathrm{X}_{1}+\beta_{2} \mathrm{X}_{2}+\beta_{3} \mathrm{X}_{3}+\beta_{11} \mathrm{X}^{2}{ }_{11}+\beta_{22} \mathrm{X}_{22}^{2}+\beta_{33} \mathrm{X}^{2}{ }_{33}+$ $\beta_{12} X_{1} X_{2}+\beta_{13} X_{1} X_{3}+\beta_{23} X_{2} X_{3}$

The above equation is second order polynomial equation for 3 variables. Where $\beta$ are constant, $X_{1}$, $\mathrm{X}_{2}, \mathrm{X}_{3}$ are the linear terms, $\mathrm{X}_{12} \mathrm{X}_{13} \mathrm{X}_{23}$ are the interaction terms between the factors, and lastly $\mathrm{X}_{11}$ $\mathrm{X}_{22} \mathrm{X}_{33}$ are the square terms.

$\mathrm{Q}_{\text {(heat due to convection) }}=$ response variable \& $\mathrm{A}, \mathrm{dT}, \mathrm{RH}=$ predictor variable.

Polynomial regression equation becomes after replacing real problem variables

$\mathrm{Q}_{\text {(heat due to convection) }}=\beta_{0}+\beta_{1}(\mathrm{~A})+\beta_{2}(\mathrm{dT})+\beta_{3}(\mathrm{RH})+\beta_{11}$ $(\mathrm{A}) *(\mathrm{~A})+\beta_{22}(\mathrm{dT}) *(\mathrm{dT})+\beta_{33}(\mathrm{RH}) *(\mathrm{RH})+\beta_{12}(\mathrm{~A}) *(\mathrm{dT})+$ $\beta_{13}(\mathrm{~A}) *(\mathrm{RH})+\beta_{23}(\mathrm{dT}) *(\mathrm{RH})$

To solve this equation following matrix method is used

$\mathrm{Q}=[\beta][\mathrm{X}]$.

$[\beta]=[Q]\left[X^{-1}\right]$ where $[\beta]$ is the coefficient matrix, $Y$ is the response variable matrix; $\left[\mathrm{X}^{-1}\right]$ is the inverse of predictor variable matrix.

In this problem there are 3 independent variables and each variable has 3 levels and hence from the Taguchi Orthogonal Array (OA) table L9 OA is best selected.

Table no- 2, Taguchi's L9 Orthogonal Array

\begin{tabular}{|c|c|c|c|}
\hline \multirow{2}{*}{ S1. No. } & \multicolumn{3}{|c|}{ Factorial combination } \\
\cline { 2 - 4 } & A & dT & RH \\
\hline $\mathbf{1}$ & 1 & 1 & 1 \\
\hline $\mathbf{2}$ & 1 & 2 & 2 \\
\hline $\mathbf{3}$ & 1 & 3 & 3 \\
\hline $\mathbf{4}$ & 2 & 1 & 2 \\
\hline $\mathbf{5}$ & 2 & 2 & 1 \\
\hline $\mathbf{6}$ & 2 & 3 & 3 \\
\hline $\mathbf{7}$ & 3 & 1 & 3 \\
\hline $\mathbf{8}$ & 3 & 2 & 1 \\
\hline $\mathbf{9}$ & 3 & 3 & 2 \\
\hline
\end{tabular}


Experiments have been carried out using Taguchi's L9 Orthogonal array experimental design which consists of 9 combinations of area, relative humidity and temperature difference. It considers three process parameters to be varied three discrete levels. In the equation (1) number of unknown constant (i.e. $\beta$ ) is ten and in using Taguchi's L9 Orthogonal array experimental design which consists of 9 combinations of area, relative humidity and temperature difference so to form $X$ as a $10 * 10$ matrix, $\beta$ as a $10 * 1$ matrix and $Q$ as a $10 * 1$ matrix we have taken a combination of area, relative humidity and temperature difference which does not match with any of combination of the L9 orthogonal array mentioned above. As we are working on three level value of the factors and the first column of L18 orthogonal is of 2 level so have omit this and took a combination of next three column and we have chosen a combination $3,1,2$ it does not match with any of combination of the L9 orthogonal array. Another reason to chose particular 3, 1, 2 combination is we can find the same combination in L9 orthogonal array if the first factor is omitted means omitting of the first column we can find the same combination in factor 2, factor3 and factor 4's arrangement. So the desired combination is,

Table no- 3

\begin{tabular}{|c|c|c|c|}
\hline \multirow{2}{*}{ Sl. No. } & \multicolumn{3}{|c|}{ Factorial combination } \\
\cline { 2 - 4 } & $\mathbf{A}$ & $\mathbf{d T}$ & $\mathbf{R H}$ \\
\hline $\mathbf{1}$ & 1 & 1 & 1 \\
\hline $\mathbf{2}$ & 1 & 2 & 2 \\
\hline $\mathbf{3}$ & 1 & 3 & 3 \\
\hline $\mathbf{4}$ & 2 & 1 & 2 \\
\hline $\mathbf{5}$ & 2 & 2 & 3 \\
\hline $\mathbf{6}$ & 2 & 3 & 3 \\
\hline $\mathbf{7}$ & 3 & 1 & 1 \\
\hline $\mathbf{8}$ & 3 & 2 & 2 \\
\hline $\mathbf{9}$ & 3 & 3 & 2 \\
\hline $\mathbf{1 0}$ & 3 & 1 & 3 \\
\hline
\end{tabular}

In the equation (2) $\mathrm{X}$ is a $10 * 10$ matrix, $\beta$ is a $10 * 1$ matrix and $\mathrm{Q}$ is a $10 * 1$ matrix. By using the modified L9 Orthogonal array and its iteration terms we have to find out the betas $(\beta)$ values.

Now there are ten test runs, so there will be ten values of $\mathrm{Q}$ and also ten equations. These equations are-

$\mathrm{Q}_{1}=\beta_{0}+0.5407 \beta_{1}+2 \beta_{2}+.85 \beta_{3}+0.2923 \beta_{4}+4 \beta_{5}+0.7225 \beta_{6}+1.0814 \beta_{7}+0.4596 \beta_{8}+1.7 \beta_{9}$

$\mathrm{Q}_{2}=\beta_{0}+0.5407 \beta_{1}+5 \beta_{2}+.90 \beta_{3}+0.2923 \beta_{4}+25 \beta_{5}+.81 \beta_{6}+2.7035 \beta_{7}+0.4866 \beta_{8}+4.75 \beta_{9}$

$\mathrm{Q}_{3}=\beta_{0}+0.5407 \beta_{1}+8 \beta_{2}+.95 \beta_{3}+0.2923 \beta_{4}+64 \beta_{5}+.9025 \beta_{6}+4.3256 \beta_{7}+0.5136 \beta_{8}+7.6 \beta_{9}$

$\mathrm{Q}_{4}=\beta_{0}+0.6508 \beta_{1}+2 \beta_{2}+.90 \beta_{3}+0.4235 \beta_{4}+4 \beta_{5}+.81 \beta_{6}+1.3016 \beta_{7}+0.5857 \beta_{8}+1.8 \beta_{9}$

$\mathrm{Q}_{5}=\beta_{0}+0.6508 \beta_{1}+5 \beta_{2}+.95 \beta_{3}+0.4235 \beta_{4}+25 \beta_{5}+.9025 \beta_{6}+3.254 \beta_{7}+0.6182 \beta_{8}+4.75 \beta_{9}$

$\mathrm{Q}_{6}=\beta_{0}+0.6508 \beta_{1}+8 \beta_{2}+.85 \beta_{3}+0.4235 \beta_{4}+64 \beta_{5}+.7225 \beta_{6}+5.2064 \beta_{7}+0.5532 \beta_{8}+6.8 \beta_{9}$

$\mathrm{Q}_{7}=\beta_{0}+0.8204 \beta_{1}+2 \beta_{2}+.95 \beta_{3}+0.6730 \beta_{4}+4 \beta_{5}+.9025 \beta_{6}+1.6408 \beta_{7}+0.7794 \beta_{8}+1.9 \beta_{9}$

$\mathrm{Q}_{8}=\beta_{0}+0.8204 \beta 1+5 \beta_{2}+.85 \beta_{3}+0.6730 \beta_{4}+25 \beta_{5}+.7225 \beta_{6}+4.102 \beta_{7}+0.6973 \beta_{8}+4.25 \beta_{9}$

$\mathrm{Q}_{9}=\beta_{0}+0.8204 \beta_{1}+8 \beta_{2}+.90 \beta_{3}+0.6730 \beta_{4}+64 \beta_{5}+.81 \beta_{6}+6.5632 \beta_{7}+0.7383 \beta_{8}+7.2 \beta_{9}$

$\mathrm{Q}_{10}=\beta_{0}+0.8204 \beta_{1}+2 \beta_{2}+.90 \beta_{3}+0.6730 \beta_{4}+4 \beta_{5}+.81 \beta_{6}+1.6408 \beta_{7}+0.7383 \beta_{8}+1.8 \beta_{9}$

The values of $\mathrm{A}, \mathrm{dT}, \mathrm{RH}, \mathrm{A}^{2}, \mathrm{dT}^{2}, \mathrm{RH}^{2}, \mathrm{~A}^{*} \mathrm{dT}, \mathrm{A}^{*} \mathrm{RH}, \mathrm{dT} * \mathrm{RH}$ can be found out by the following table-

Table no. 4 Observation table with square and interaction terms-

\begin{tabular}{|c|c|c|c|c|c|c|c|c|c|c|}
\hline Test runs & & $\mathrm{A}$ & $\mathrm{dT}$ & $\mathrm{RH}$ & $\mathrm{A}^{*} \mathrm{~A}$ & $\mathrm{dT} * \mathrm{dT}$ & $\mathrm{RH} \mathrm{RH}^{*}$ & $\mathrm{~A} * \mathrm{dT}$ & $\mathrm{A} * \mathrm{RH}$ & $\mathrm{dT} \mathrm{RH}^{*}$ \\
\hline 1 & 1 & 0.5407 & 2 & 0.85 & 0.2923 & 4 & 0.7225 & 1.0814 & 0.4596 & 1.7 \\
\hline 2 & 1 & 0.5407 & 5 & 0.90 & 0.2923 & 25 & 0.81 & 2.7035 & 0.4866 & 4.5 \\
\hline 3 & 1 & 0.5407 & 8 & 0.95 & 0.2923 & 64 & 0.9025 & 4.3256 & 0.5136 & 7.6 \\
\hline 4 & 1 & 0.6508 & 2 & 0.90 & 0.4235 & 4 & 0.81 & 1.3016 & 0.5857 & 1.8 \\
\hline 5 & 1 & 0.6508 & 5 & 0.95 & 0.4235 & 25 & 0.9025 & 3.254 & 0.6182 & 4.75 \\
\hline 6 & 1 & 0.6508 & 8 & 0.85 & 0.4235 & 64 & 0.7225 & 5.2064 & 0.5532 & 6.8 \\
\hline 7 & 1 & 0.8204 & 2 & 0.95 & 0.6730 & 4 & 0.9025 & 1.6408 & 0.7794 & 1.9 \\
\hline 8 & 1 & 0.8204 & 5 & 0.85 & 0.6730 & 25 & 0.7225 & 4.102 & 0.6973 & 4.25 \\
\hline 9 & 1 & 0.8204 & 8 & 0.90 & 0.6730 & 64 & 0.81 & 6.5632 & 0.7383 & 7.2 \\
\hline 10 & 1 & 0.8204 & 2 & 0.90 & 0.6730 & 4 & 0.81 & 1.6408 & 0.7383 & 1.8 \\
\hline & $\mathrm{C} 1$ & $\mathrm{C} 2$ & $\mathrm{C} 3$ & $\mathrm{C} 4$ & $\mathrm{C} 5$ & $\mathrm{C} 6$ & $\mathrm{C} 7$ & $\mathrm{C} 8$ & $\mathrm{C} 9$ & $\mathrm{C} 10$ \\
\hline
\end{tabular}




\section{Heat Calculation}

In this study heat transfer from evaporating space to refrigerant (which are in tube or pipe) only being considered.The transfer heat evaporating space to refrigerant are calculated in terms of Area of the evaporator with fin(A), temperature difference ( $\mathbf{d T}$ ) $\&$ relative humidity $\mathrm{RH})$. Only convection heat transfer effect is being considered in this study.

Basic equation for heat transfer

$\mathrm{Q}_{\mathrm{T}}=\mathrm{Q}_{\text {conv }}+\mathrm{Q}_{\text {condensation }}$.

$\left.\mathrm{Q}_{\text {conv }}=\mathrm{Ah}_{\mathrm{c}} \mathrm{dT} \& \mathrm{Q}_{\text {condensation }}=\mathrm{Ah}_{\mathrm{m}} \mathrm{RH}\right) \mathrm{h}_{\mathrm{fg} \text {. [3] }}$ [3]

Here $\mathrm{Q}_{\text {conv }}=$ heat transfer due to convection $\& \mathrm{Q}_{\text {condensation }}=$ heat transfer due to condensation \&

$\mathrm{Q}_{\mathrm{T}}=$ Total heat transfer or absorb heat into refrigerant.

$\mathrm{Q}_{\mathrm{T}}=\mathrm{Ah}_{\mathrm{c}} \mathrm{dT}+\mathrm{Ah}_{\mathrm{m}}(\mathrm{RH}) \mathrm{h}_{\mathrm{fg}}$

or, $\mathrm{Q}_{\mathrm{T}}=\left[\mathrm{Ah}_{\mathrm{c}} \mathrm{dT}\right]+\left[\left(\mathrm{h}_{\mathrm{c}} / 1.005\right) \cdot \mathrm{A} \cdot \mathrm{RH} \cdot \mathrm{h}_{\mathrm{fg}}\right]$

[As we know, $h_{\mathrm{c}} / \mathrm{h}_{\mathrm{m}}=\mathrm{c}_{\mathrm{p}}(\mathrm{Le})^{2 / 3}$

$$
\text { or, } \mathrm{h}_{\mathrm{c}} / \mathrm{h}_{\mathrm{m}}=1.005(1)^{2 / 3}
$$$$
\text { or, } \mathrm{h}_{\mathrm{c}}=\mathrm{h}_{\mathrm{m}} \text { ] }
$$

or, $\mathrm{Q}_{\mathrm{T}}=\mathrm{Ah}_{\mathrm{c}}\left[\mathrm{dT}+\left(\mathrm{RH} \cdot \mathrm{h}_{\mathrm{fg}}\right) / 1.005\right]$

or, $\mathrm{Q}_{\mathrm{T}}=\mathrm{A} \cdot \mathrm{h}_{\mathrm{c}}\left(\mathrm{dT}+\mathrm{RH} \cdot \mathrm{h}_{\mathrm{fg}}\right)$

The heat transfer equation due to area of the evaporator with fin $(\mathbf{A})$, temperature difference $(\mathbf{d T})$ $\&$ relative humidity $\mathrm{RH})$ is $\mathbf{Q}_{\mathbf{T}}=\mathbf{A} \mathbf{h}_{\mathbf{c}}(\mathbf{d T}+\mathbf{2 4 9 0}$ RH).................(4) [8]

Here, $\mathbf{A}=$ surface area of tubes in evaporator with fin $\mathbf{h}_{\mathbf{c}}=$ convective heat transfer co-efficient.

$\mathbf{h}_{\mathrm{m}}=$ convective mass transfer co-efficient,

$\mathbf{h}_{\mathrm{fg}}=$ latent heat of condensation of moisture 2490

$\mathrm{KJ} / \mathrm{Kg}-\mathrm{K}$.

$\mathbf{C}_{\mathbf{p}}=$ specific heat of air $1.005 \mathrm{KJ} / \mathrm{Kg}-\mathrm{K}$.

$\mathbf{L e}=$ Lewis number for air it is one.

Now we calcutate the value of convective heat transfer co-efficient $\left(\mathrm{h}_{\mathrm{c}}\right)$,

We know,

$\mathrm{Nu}=\frac{\text { Convective heat transfer }}{\text { Conductive heat transfer }}=\left(\mathrm{h}_{\mathrm{c}} * \mathbf{L}\right) / \mathrm{k}$

Where:

$\mathrm{Nu}=$ Nusselt number

$\mathrm{hc}=$ convective heat transfer coefficient

$\mathrm{k}=$ thermal conductivity, $\mathrm{W} / \mathrm{mK}$

$\mathrm{L}=$ characteristic length, $\mathrm{m}$

The convection heat transfer coefficient is then defined as following:

$$
h_{c}=\frac{N u * K}{L}
$$

The Nusselt number depends on the geometrical shape of the heat sink and on the air flow. For natural convection on flat isothermal plate the formula is given in table

Nusselt number formula.

Table no. 5

\begin{tabular}{|l|l|l|l|}
\hline & Vertical fins & & Horizontal fins \\
\hline Laminar flow & $\mathrm{Nu}=0.59 * \mathrm{Ra}^{0.25}$ & Upward laminar flow & $\mathrm{Nu}=0.54 * \mathrm{Ra}^{0.25}$ \\
\hline Turbulent flow & $\mathrm{Nu}=0.14 * \mathrm{Ra}^{0.33}$ & Downward laminar flow & $\mathrm{Nu}=0.27 * \mathrm{Ra}^{0.25}$ \\
\hline & & Turbulent flow & $\mathrm{Nu}=0.14 * \mathrm{Ra}^{0.33}$ \\
\hline
\end{tabular}

Where:

$$
\mathbf{R a}=\mathbf{G r} * \operatorname{Pr}
$$

The Rayleigh number(Ra) defined in terms of Prandtl number (Pr) and Grashof number (Gr).

If , $R \mathbf{a}<\mathbf{1 0}^{9}$ the heat flow is laminar,

while $R a>106$ the flow is turbulent.

\section{Grashof number (Gr):}

$$
\mathbf{G r}=\frac{g * L^{3} * \boldsymbol{\alpha} *(\boldsymbol{T a}-\boldsymbol{T} \boldsymbol{p})}{\boldsymbol{\eta}^{2}} \quad \text { [for natural convective heat transfer from a cold body] }
$$

Where:

- $\mathrm{g}=$ acceleration of gravity $=9.81, \mathrm{~m} / \mathrm{s} 2$

- $\mathrm{L}=$ longer side of the fin $=30$ foot $=9.144 \mathrm{~m}$

- $\alpha=$ air thermal expansion coefficient. For gases, is the reciprocal of the temperature in Kelvin:

$\alpha=\frac{1}{\mathrm{Ta}}, 1 / \mathrm{K}=(1 / 275.15) \mathrm{K}$

$-\mathrm{T}_{\mathrm{p}}=$ Plate temperature, $=272.15 \mathrm{~K}$

$-\mathrm{T}_{\mathrm{a}}=$ Air temperature $=275.15 \mathrm{~K}$

- $\eta=$ air kinematic viscosity $=13.39 * 10^{-6} \mathrm{~m}^{2} / \mathrm{s}$ [at air temp. $=275.15 \mathrm{~K} \&$ air pressure $=1$ bar $]$

$$
\mathrm{Gr}=\frac{9.81 *(9.144)^{3} *\left(\frac{1}{275.15}\right) *(275.15-272.15)}{\left(13.39 * 10^{-6}\right)^{2}}
$$




$$
\text { or, } \mathrm{Gr}=4.56 * 10^{11}
$$

\section{Prandtl number (Pr):}

Where:

$$
\operatorname{Pr}=\frac{\mu * c p}{K}
$$

- $\mu$ = air dynamic viscosity, is $1.725 * 10^{-5} \mathrm{~kg} / \mathrm{m} . \mathrm{s}$ at $275.15 \mathrm{~K}$

- $\mathrm{cp}=$ air specific heat $=1005 \mathrm{~J} /(\mathrm{Kg} * \mathrm{~K})$ for dry air

- $\mathrm{k}=$ air thermal conductivity $=0.0244 \mathrm{~W} /(\mathrm{m} * \mathrm{~K})$ at $275.15 \mathrm{~K}$

So,

$$
\begin{array}{r}
\operatorname{Pr}=\frac{1.725 * 10^{-5} * 1005}{\mathbf{0 . 0 2 4 4}} \\
\operatorname{Or}, \operatorname{Pr}=0.711
\end{array}
$$

$\mathbf{R a}=\mathbf{G r} * \mathbf{P r}$

$\operatorname{Ra}=4.56 * 10^{11} * 0.711$

$\operatorname{Ra}=3.24 * 10^{11}$

As, $\mathrm{Ra}>10^{9}=$ Turbulent flow

So, Nustle Number for turbulent flow,

$\mathrm{Nu}=0.14 * \mathrm{Ra}^{0.33}$

$\mathrm{Nu}=0.14 *\left(3.24 * 10^{11}\right)^{0.33}$

$\mathrm{Nu}=880.25$

So, Convective Heat Transfer co-efficient $\left(\mathrm{h}_{\mathrm{c}}\right)$ :-

$h_{c}=\frac{880.25 * 0.0244}{9.144}$

or, $\mathbf{h}_{\mathbf{c}}=\mathbf{2 . 3 5}$

So, The final Heat Transfer equation when we replace the $h_{c}$ in equation (4) we get,

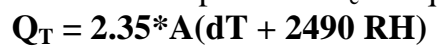

\section{Annular Pin Fin}

In thermal engineering, an annular fin is a specific type of fin used in heat transfer that varies, radially, in cross-sectional area. Adding an annular fin to an object increases the amount of surface area in contact with the surrounding fluid, which increases the convective heat transfer between the object and

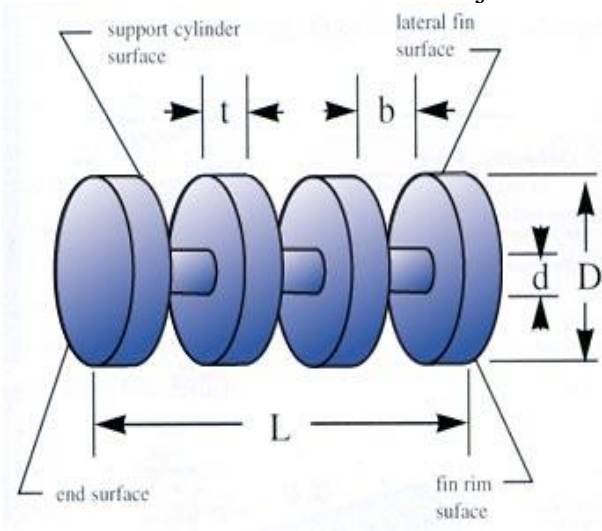

surrounding fluid. Because surface area increases as length from the object increases, an annular fin transfers more heat than a similar pin fin at any given length. Annular fins are often used to increase the heat exchange in liquid-gas heat exchanger systems.

Fig.1 Configuration of Annular pin fin 
We assume,

Total $\operatorname{Area}\left(\mathrm{A}_{\mathrm{T})}=\mathrm{A}_{\mathrm{b}}+\mathrm{A}_{\mathrm{f}}\right.$

Annular pin fin Area calculation,

Circumference of fin (C):

$$
\mathrm{C}=\mathbf{2} \pi * \mathrm{r}_{2} * \mathrm{t}
$$

Cross-sectional area of fin (A):

$$
A=2 \pi\left(r_{2}^{2}-r_{1}^{2}\right)
$$

Fin area available for heat transfer:

$$
A_{f}=\left[2 \pi\left(r_{2}^{2}-r_{1}^{2}\right)+2 \pi^{*} r_{2 *} t\right] * N
$$

Circumference of bare tube $\left(\mathrm{C}_{\mathrm{b}}\right)$ :

$$
C_{b}=2 \pi * r_{1} * L
$$

Cross-sectional area of bare tube $\left(\mathrm{A}_{\mathrm{b}}\right)$ :

$$
A_{b}=2 \pi^{*} r_{1}{ }^{2}
$$

Tube area available for heat transfer in finned tube heat exchanger:

Where,

$$
A_{b}=\left(2 \pi * r_{1} * L-2 \pi * r_{1} * t * N\right)+2 \pi * r_{1}^{2}
$$

$A_{b}=$ Tube area available for heat transfer in finned tube heat exchanger

$A_{f}=$ Fin area available for heat transfer

$\mathrm{A}_{\mathrm{T}}=$ Total Area

$\mathrm{r}_{1}=$ Outer radius of bare tube

$\mathrm{r}_{2}=$ Outer radius of annular fin

$\mathrm{t}=$ Thickness of annular fin

$\mathrm{L}=$ Length of bare tube

$\mathrm{D}=$ Outer diameter of annular fin

$\mathrm{d}=$ Outer diameter of bare tube

$\mathrm{b}=$ gap between two annular fin

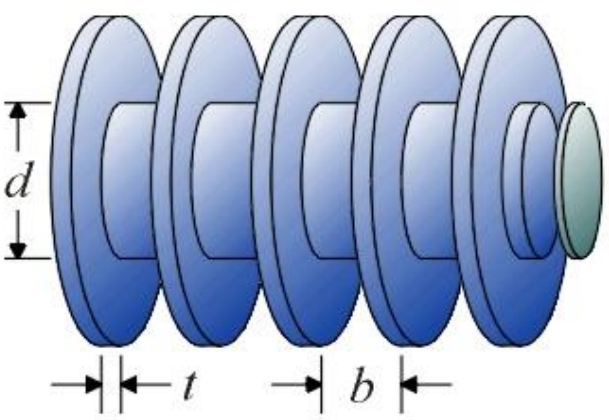

$\mathrm{n}=$ Number of bare tube $=1$

$\mathrm{N}=$ Number of annular fin

\section{Area Calculation:}

Measured data-

$\mathrm{r}_{1}=14 \mathrm{~mm}=0.014 \mathrm{~m}$

$\mathrm{r}_{2}=32.63 \mathrm{~mm}=0.03263 \mathrm{~m}$

$\mathrm{t}=1 \mathrm{~mm}=0.001 \mathrm{~m}$

$\mathrm{b}=11.44 \mathrm{~mm}=0.01144 \mathrm{~m}$

No. Of fin in one meter $=81$

Tube area available for heat transfer in finned tube heat exchanger $\left(\mathrm{A}_{\mathrm{b}}\right)$

$$
\begin{aligned}
& \mathrm{A}_{\mathrm{b}}=\left[\left(2 \pi * \mathrm{r}_{1} * \mathrm{~L}-2 \pi^{*} \mathrm{r}_{1} * \mathrm{t} * \mathrm{~N}\right)+2 \pi^{*} \mathrm{r}_{1}{ }^{2}\right]^{* \mathrm{n}} \\
& =\left[\left(2 \pi * 0.014 * 1-2 \pi^{*} 0.014 * 0.001 * 81\right)+\right. \\
& \left.2 \pi^{*}(14)^{2}\right]^{*} 1 \\
& \quad=0.0820 \mathrm{~m}^{2}
\end{aligned}
$$

Fin area available for heat transfer

$$
\begin{gathered}
\mathrm{A}_{\mathrm{f}}=\left[2 \pi\left(\mathrm{r}_{2}^{2}-\mathrm{r}_{1}^{2}\right)+2 \pi^{*} \mathrm{r}_{2} * \mathrm{t}\right] * \mathrm{~N} \\
=\left[2 \pi\left\{(0.03263)^{2}-(0.014)^{2}\right\}+\right. \\
2 \pi *(0.03263) * 1] * 81 \\
=0.4587 \mathrm{~m}^{2}
\end{gathered}
$$

So,

Total Area of heat transfer,

$\mathrm{A}_{\mathrm{T}}=(0.0820+0.4587) \mathrm{m}^{2}$ $=0.5407 \mathrm{~m}^{2}$

\section{Annular fin arrangement:}

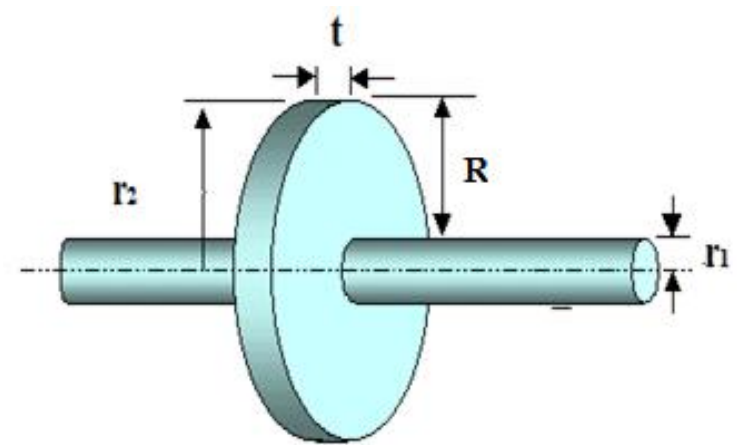

Fig.2 Arrangment of Pin fin

Where we assume,

$\mathrm{b}=$ Spacing between two annular fin $=\left(0.8 * \mathrm{r}_{1}\right)$

Now, From equation number (6) we have $\mathrm{Q}_{1 \ldots \ldots 10}$

values by putting the values of Area of the evaporator with fin (A) from the equation of Area(A), Relative humidity $(\mathrm{RH})$ and temperature difference (dT).

Table no. 6 Response variable matrix -

\begin{tabular}{|c|}
\hline $\mathrm{Q}$ \\
\hline 2691.86 \\
\hline 2853.87 \\
\hline 3015.87 \\
\hline 3430.40 \\
\hline 3625.39 \\
\hline 3249.17 \\
\hline 4564.40 \\
\hline 4090.12 \\
\hline 4335.94 \\
\hline 4324.37 \\
\hline
\end{tabular}


Now using the equation number (3) we get the coefficient matrix $[\beta]-$
We use MATLAB software to find out the coefficient matrix $[\beta]$,

Table no. 7 Regression coefficient table

\begin{tabular}{|c|c|}
\hline $\mathrm{B}_{0}$ & -47.3924 \\
\hline $\mathrm{B}_{1}$ & 0.6457 \\
\hline $\mathrm{B}_{2}$ & -2.0211 \\
\hline $\mathrm{B}_{3}$ & 115.5284 \\
\hline $\mathrm{B}_{4}$ & -11.3775 \\
\hline $\mathrm{B}_{5}$ & -0.0266 \\
\hline $\mathrm{B}_{6}$ & -79.6236 \\
\hline $\mathrm{B}_{7}$ & 1.9672 \\
\hline $\mathrm{B}_{8}$ & 5871.7686 \\
\hline $\mathrm{B}_{9}$ & 2.8907 \\
\hline
\end{tabular}

After putting the values of regression coefficient in equation no- (1) The final regression equation becomes-

$Q_{\text {(heat due to convection heat transfer) }}=-47.3924+0.6457(A)$ 2.0211(dT) + 115.5284(RH) - 11.3775(A) (A) $0.0266(\mathrm{dT})(\mathrm{dT})-\mathbf{7 9 . 6 2 3 6}(\mathrm{RH})(\mathrm{RH})+1.9672(\mathrm{~A})$ $(d T)+5871.7686(A)(R H)+\mathbf{2 . 8 9 0 7}(d T)(R H)$

This is the proposed regression equation. It establishes the relationship between the response variable $\mathrm{Q}$ and the predictor variables i.e. control variables $\mathrm{A}, \mathrm{dT}$, and $\mathrm{RH}$. By the help of above equation the heat transfer evaporator space to evaporator coil can easily be computed. With the help of the multiple regression equation a computer program has been generated to check the effect of variations of control parameters on output variable. With the help of data sets generated by the program various graphs are drawn.

\section{RESULTS AND DISCUSSIONS}

\section{Regression analysis}

A computer program has been written in ' $\mathrm{C}$ ' language on the basis of the 2nd order nonlinear equation which is obtained through regression analysis. The program consists of three parts each for analyzing the variation of control factor with the output parameter. While varying one control factor with the output other two factors were kept at a constant value.

\section{a. Effect of area of the evaporator on heat transfer rate -}

The values of dT and RH remain constant. Enter the value for A within the range 0.5407 to 0.8204, Start with 0.5407 keeping $\mathrm{dT}=2$ and $\mathrm{RH}=0.95$ and incrementing the value of A by 0.025 , the corresponding values of Q. Graph 1 of Fig.3 shows that heat absorption increase with area of the evaporator increases. By using computer program data set the variation of A with $\mathrm{Q}$ can be graphically represented as

\section{b. Effect of temperature difference on heat transfer rate-}

The values of $\mathrm{A}$ and $\mathrm{RH}$ remain constant. Enter the value for dT within the range 2 to 8 , Start with 2.0, Keeping $\mathrm{A}=0.6508$ and $\mathrm{RH}=0.95$ and incrementing the value of $\mathrm{dT}$ by 0.5 , the corresponding values of $\mathrm{Q}$. By using the computer program data set the variation of $\mathrm{dT}$ with $\mathrm{Q}$ can be graphically represented on graph 2 of Fig.3.

\section{c. Effect of relative humidity on heat transfer rate-}

First, the values of $\mathrm{A}$ and $\mathrm{dT}$ remain constant. Enter the value for $\mathrm{RH}$ within the range 0.85 to 0.95 , Start with 0.85 Keeping $A=0.6508$ and $\mathrm{dT}=2$ and incrementing the value of $\mathrm{RH}$ by 0.01 , the corresponding values of $\mathrm{Q}$. By using the computer program data set the variation of $\mathrm{RH}$ with $\mathrm{Q}$ can be graphically represented on graph 3 of Fig. 3 . 


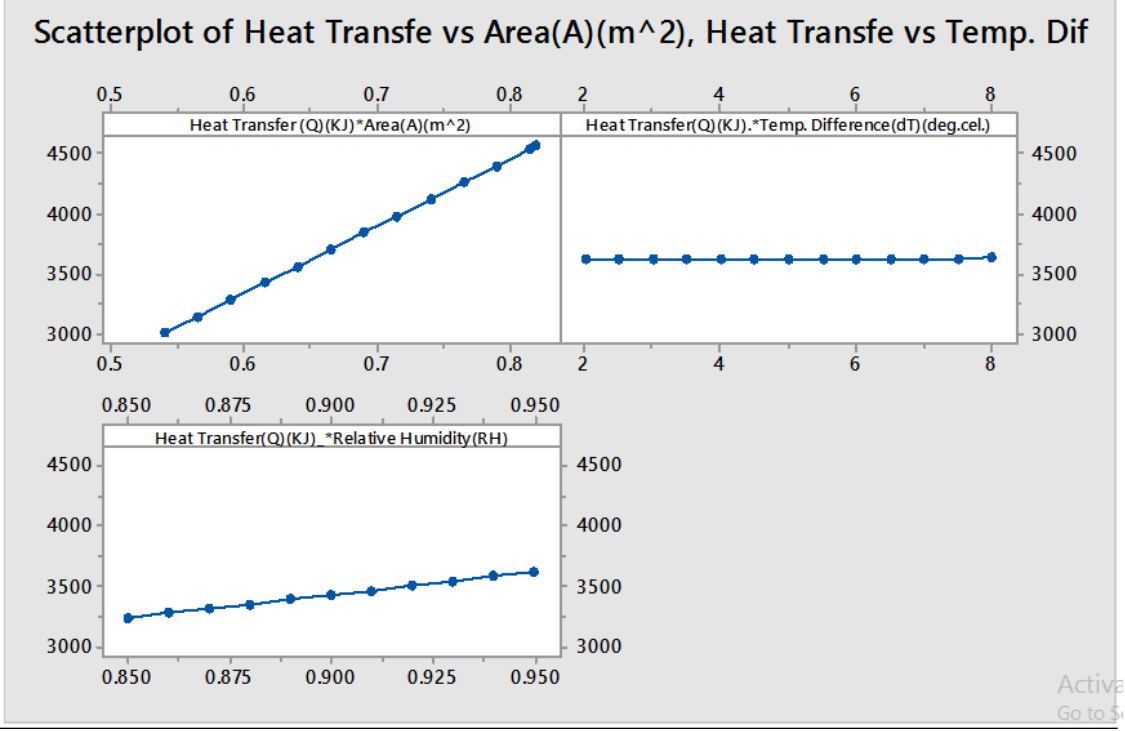

Figure 3: variation of heat transfer with area, temp. difference \& relative humidity.

\section{S/N Ratio Analysis}

The signal to noise ratios $(\mathrm{S} / \mathrm{N})$, which are $\log$ functions of desired output, serve as the objective functions for optimization, help in data analysis and the prediction of the optimum results. There are 3 types of $\mathrm{S} / \mathrm{N}$ ratios are available-namely smaller the better, larger the better \& nominal is the best. In this problem we both use larger-the-better types $\mathrm{S} / \mathrm{N}$ ratio. In case of conduction process we use largerthe-better type $\mathrm{S} / \mathrm{N}$ ratio to maximize the heat flow from inside of the cold room to outside through the evaporator. Ratio to maximize the heat transfer in the evaporator space of the cold room.

\section{For conduction process \\ Smaller-the-better}

This is expressed as $-(\mathrm{S} / \mathrm{N})=-10 \log 10$ (mean of sum of squares of measured data) This is usually the chosen $\mathrm{S} / \mathrm{N}$ ratio for all the undesirable characteristics like "defects" for which the ideal value is zero. When an ideal value is finite and its maximum or minimum value is defined (like the maximum purity is $100 \%$ or the maximum temperature is $92 \mathrm{~K}$ or the minimum time for making a telephone connection is $1 \mathrm{sec}$ ) then the difference between the measured data and the ideal value is expected to be as small as possible. Thus, the generic form of $\mathrm{S} / \mathrm{N}$ ratio becomes- $(\mathrm{S} / \mathrm{N})=-10 \log 10$ mean of sum of squares of (measured-ideal) data

For experiment no-7

SN7 $=-10 \log \left[\Sigma\left\{1 /(4564.40)^{2}\right\} / 1\right]=73.1877$ Where, $Q 7=4564.40 \& n=1$

For experiment no-8

SN8 $=-10 \log \left[\Sigma\left\{1 /(4090.12)^{2}\right\} / 1\right]=72.2347$ Where, Q8=4090.12 \& $n=1$

For experiment no- 9

SN9 $=-10 \log \left[\Sigma\left\{1 /(4335.94)^{2}\right\} / 1\right]=72.7416$ Where, Q9=4335.94 \& $n=1$

\section{For convection and condensation process} Larger-the-better

For calculating $\mathrm{S} / \mathrm{N}$ ratio for larger the better for maximum heat transfer, the equation is $\mathrm{SN}_{\mathrm{i}}=-10 \log \left[\sum\left\{1 /\left(\mathrm{Q}_{\mathrm{i}}\right)^{2}\right\} / \mathrm{n}\right] \quad \ldots \ldots .(7)$

Where $n=$ number of trials in a row

$\mathrm{Q}_{\mathrm{i}}=$ calculated value in the test run or row.

Trial number $=\mathrm{i}$

$\mathrm{SN}_{\mathrm{i}}=\mathrm{S} / \mathrm{N}$ ratio for respective result

For experiment no-1

$\mathrm{SN} 1=-10 \log \left[\Sigma\left\{1 /(2691.86)^{2}\right\} / 1\right]=68.6010$ Where, $\mathrm{Q} 1=2691.86 \& \mathrm{n}=1$

For experiment no-2

$\mathrm{SN} 2=-10 \log \left[\Sigma\left\{1 /(2853.87)^{2}\right\} / 1\right]=69.1087$ Where, $\mathrm{Q} 2=2853.87 \& \mathrm{n}=1$

For experiment no-3

SN3 $=-10 \log \left[\Sigma\left\{1 /(3015.87)^{2}\right\} / 1\right]=69.5882$ Where,

$\mathrm{Q} 3=3015.87 \& \mathrm{n}=1$

For experiment no-4

SN4 $=-10 \log \left[\Sigma\left\{1 /(3430.40)^{2}\right\} / 1\right]=70.7069$ Where,

$\mathrm{Q} 4=3430.40 \& \mathrm{n}=1$

For experiment no-5

SN5 $=-10 \log \left[\Sigma\left\{1 /(3625.39)^{2}\right\} / 1\right]=71.1871$ Where, $\mathrm{Q} 5=3625.39 \& \mathrm{n}=1$

For experiment no-6

SN6 $=-10 \log \left[\Sigma\left\{1 /(3249.17)^{2}\right\} / 1\right]=70.2354$ Where, $\mathrm{Q} 6=3249.17 \& \mathrm{n}=1$ 

ISSN : 2248-9622, Vol. 7, Issue 6, ( Part -6) June 2017, pp.33-43

Table no.8 S/N Ratio Larger the better

\begin{tabular}{|c|c|c|c|c|c|c|c|c|}
\hline \multirow{3}{*}{$\begin{array}{l}\text { Exp. } \\
\text { No. }\end{array}$} & \multicolumn{6}{|c|}{ Parameter } & \multirow{3}{*}{$\begin{array}{c}\text { Heat Transfer } \\
(\mathrm{KJ})\end{array}$} & \multirow{3}{*}{$\begin{array}{c}\text { S/N Ratio } \\
\text { Larger The } \\
\text { Better }\end{array}$} \\
\hline & \multirow{2}{*}{\multicolumn{3}{|c|}{$\begin{array}{c}\text { Combination of } \\
\text { Control Parameter }\end{array}$}} & \multicolumn{3}{|c|}{ Control Parameter } & & \\
\hline & & & & \multirow{2}{*}{$\begin{array}{c}\begin{array}{c}\text { Area } \\
\left(\mathrm{m}^{2}\right)\end{array} \\
0.5407\end{array}$} & \multirow{2}{*}{$\begin{array}{c}\text { Temperature } \\
\text { difference }\left(0_{c}\right)\end{array}$} & \multirow{2}{*}{$\begin{array}{c}\begin{array}{c}\text { Relative } \\
\text { Humidity }(\%)\end{array} \\
0.85 \\
\end{array}$} & & \\
\hline 1 & 1 & 1 & 1 & & & & 2691.86 & 68.6010 \\
\hline 2 & 1 & 2 & 2 & 0.5407 & 5 & 0.90 & 2853.87 & 69.1087 \\
\hline 3 & 1 & 3 & 3 & 0.5407 & 8 & 0.95 & 3015.87 & 69.5882 \\
\hline 4 & 2 & 1 & 2 & 0.6508 & 2 & 0.90 & 3430.40 & 70.7069 \\
\hline 5 & 2 & 2 & 3 & 0.6508 & 5 & 0.95 & 3625.39 & 71.1871 \\
\hline 6 & 2 & 3 & 1 & 0.6508 & 8 & 0.85 & 3249.17 & 70.2354 \\
\hline 7 & 3 & 1 & 3 & 0.8204 & 2 & 0.95 & 4564.40 & 73.1877 \\
\hline 8 & 3 & 2 & 1 & 0.8204 & 5 & 0.85 & 4090.12 & 72.2347 \\
\hline 9 & 3 & 3 & 2 & 0.8204 & 8 & 0.95 & 4335.94 & 72.7416 \\
\hline
\end{tabular}

\section{Overall mean of $\mathrm{S} / \mathrm{N}$ ratio}

The calculation of overall mean is done by the following process:-

A11= Mean of low level values of Area

$\mathrm{A} 11=(\mathrm{SN} 1$

$+\mathrm{SN} 2+$

$/ 3=(68.6010+69.1087+69.5882) / 3=69.0993$

A21 $=$ Mean of medium level values of Area
$\mathrm{A} 21=(\mathrm{SN} 4$
$+\mathrm{SN} 5+$

$B=(70.7069+71.1871+70.2354) / 3=70.7098$

A31 $=$ Mean of high level values of Area

$$
\text { A31 }=(\mathrm{SN} 7+\mathrm{SN} 8+
$$$$
7416) / 3=72.7213
$$

$\mathrm{dT} 22=(\mathrm{SN} 2+\mathrm{SN} 5+\mathrm{SN} 8)$

$/ 3=(69.1087+71.1871+72.2347) / 3=70.8435$

$\mathrm{dT} 32=$ Mean of high level values of Temperature difference

dT32 $=(\mathrm{SN} 3+\mathrm{SN} 6+\mathrm{SN} 9)$

$/ 3=(69.5882+70.2354+72.7416) / 3=70.8550$

SN6) RH13= Mean of low level values of Relative humidity

$\mathrm{RH} 13=(\mathrm{SN} 1+\mathrm{SN} 6+$

SN9)

$13=(73.1877+72.2347+72.7416) / 3=72.7213$

dT12 $=$ Mean of low level values of Temperature difference

$\mathrm{dT} 12=(\mathrm{SN} 1$

$+\mathrm{SN} 4+$

SN7)

$13=(68.6010+70.7069+73.1877) / 3=70.8318$

dT22 $=$ Mean of medium level values of Temperature difference
$\mathrm{SN} 8) / 3=(68.6010+70.2354+72.2347) / 3=70.3570$

RH23= Mean of medium level values of Relative humidity

$\mathrm{RH} 23=(\mathrm{SN} 2+\mathrm{SN} 4+$

SN9 $) / 3=(69.1087+70.7069+72.7416) / 3=70.8524$

RH33= Mean of high level values of Relative humidity

$\mathrm{RH} 33=(\mathrm{SN} 3+\mathrm{SN} 5+$

$\mathrm{SN} 7) / 3=(69.5882+71.1871+73.1877) / 3=71.321$

Table 9 Overall mean of S/N Ratio (Response Table for Signal to Noise Ratios Larger is better)

\begin{tabular}{|l|c|c|c|c|}
\hline Level & \multicolumn{2}{|l|}{ Average S/N Ratio by Factor Level } & $\begin{array}{l}\text { Overall Mean of S/N } \\
\text { Ratio }\left(\mathrm{SN}_{0}\right)\end{array}$ \\
\hline Low & $\begin{array}{l}\text { Temperature } \\
\text { Difference }\left(0_{\mathrm{c}}\right)\end{array}$ & $\begin{array}{l}\text { Relative } \\
\text { Humidity }(\%)\end{array}$ & \multirow{2}{*}{70.8435} \\
\hline Medium & 69.0993 & 70.8318 & 70.3570 & \\
\hline High & 70.7098 & 70.8435 & 70.8524 & \\
\cline { 1 - 3 } $\begin{array}{l}\text { Delta=larger- } \\
\text { smaller }\end{array}$ & 3.7213 & 70.8550 & 71.321 & \\
\cline { 1 - 2 } Rank & 1 & 0.0232 & 0.964 & \\
\hline
\end{tabular}

Mean S/N ratio vs Area, temperature difference and relative humidity figure.

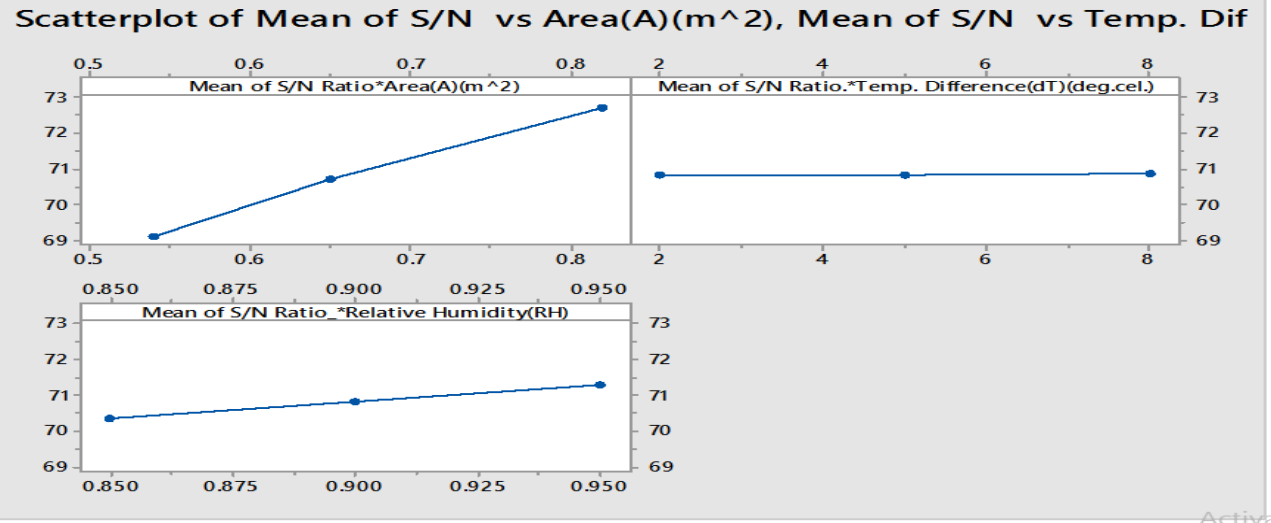

Fig. No. 4 


\section{Analysis of Variance (ANOVA) Calculation}

The test runs results were again analysed using ANOVA for identifying the significant factors and their relative contribution on the output variable. Taguchi method can not judge and determine effect of individual parameters on entire process while percentage contribution of individual parameters can be well determined using ANOVA. The tests run data in were again analysed using ANOVA at $95 \%$ confidence level $(\alpha=.05)$ for identifying the significant factors and their relative contribution on the output variable.

Table 10 The analysis was carried out in MINITAB software. The following table shows ANOVA table

\begin{tabular}{|l|l|l|l|l|l|l|l|}
\hline Source & Notation & $\begin{array}{c}\text { Degrees of } \\
\text { Freedom }\end{array}$ & $\begin{array}{c}\text { Sum of } \\
\text { Squares }\end{array}$ & $\begin{array}{c}\text { Mean } \\
\text { Squares }\end{array}$ & F Ratio & $\begin{array}{c}\text { P } \\
\text { Value }\end{array}$ & $\begin{array}{c}\text { \% } \\
\text { Contribution }\end{array}$ \\
\hline A & $\begin{array}{l}\text { Area of the } \\
\text { Bear tube \& } \\
\text { Fin }\end{array}$ & 2 & 3318446 & 1659223 & 962.82 & 0.001 & 93.3653 \\
\hline dT & $\begin{array}{l}\text { Temperature } \\
\text { Difference }\end{array}$ & 2 & 2455 & 1227 & 0.71 & 0.584 & 0.0690 \\
\hline RH & $\begin{array}{l}\text { Relative } \\
\text { Humidity }\end{array}$ & 2 & 229913 & 114957 & 66.71 & 0.015 & 6.4686 \\
\hline Error & & 2 & 3447 & 1723 & & & 0.1038 \\
\hline Total & & 8 & 3554261 & & & & 100 \\
\hline
\end{tabular}

The above calculations suggest that the area of the Evaporator has the largest influence with a contribution of $93.3653 \%$. Next is relative humidity with $6.4686 \%$ contribution and temperature difference has lowest contribution of $0.0690 \%$.

\section{CONCLUSION}

In this work study Taguchi method of design of experiment has been applied for optimizing the control parameters so as to increase heat transfer rate evaporating space to evaporating level. From the analysis of the results obtained following conclusions can be drawn-

1. From the Taguchi $\mathrm{S} / \mathrm{N}$ ratio graph analysis the optimal settings of the cold storage are Area of the Evaporator (A) $0.8204\left(\mathrm{~m}^{2}\right)$, Temperature difference (dT) $2\left({ }^{0} \mathrm{c}\right)$ and Relative humidity (RH) 0.95 in percentage. This optimality has been proposed out of the range of [A $(0.5407$, $0.6508,0.8204)$, dT $(2,5,8)$, RH $(0.85,0.90$, $0.95)]$.So, increase the evaporator Area is most important.

2. ANOVA analysis indicates Area of evaporator (A) is the most influencing control factor on $\mathrm{Q}$ and it is near about $93.3653 \%$ Next is relative humidity $6.4686 \%$ contribution

3. Results obtained both from Taguchi $\mathrm{S} / \mathrm{N}$ ratio analysis and the multiple regression analysis are also bearing the same trend.

4. The proposed model uses a theoretical heat convection model through cold storage using multiple regression analysis.

5. Taguchi L9 orthogonal array has used as design of experiments. The results obtained from the $\mathrm{S} / \mathrm{N}$ ratio analysis and ANOVA are close in values. Both have identified Area of the Evaporator (A) is the most significant control parameter followed by relative humidity $(\mathrm{RH})$, and temperature difference (dT).

\section{REFERENCE}

[1] Mälardalen University Press Licentiate Theses No. 88 "OPTIMAL PIN FIN HEAT EXCHANGER SURFACE” Hamid Nabati 2008

[2] Iterative calculation of the heat transfer coefficient by D.Roncati (Progettazione Ottica Roncati, via Panfilio, 17 - 44121 Ferrara)

[3] HEAT CONDUCTION THROUGH FINS by Prabal Talukdar, Associate Professor, Department of Mechanical Engineering, IIT Delhi

[4] E-mail: prabal@mech.iitd.ac.in

[5] Dr. N. Mukhopadhyay-A Theoretical Comparative Study of Heat Load Distribution Model of a Cold Storage. International Journal of Scientific \& Engineering Research, Volume 6, Issue 2, February-2015 516 ISSN 2229-5518.

[6] Dr. N. Mukhopadhyay- Optimization of Different Control Parameters of a Cold Storage using Taguchi Methodology,AMSE JOURNALS -2014-Series: Modelling D; Vol. 36; $\mathrm{N}^{\circ}$ 1; pp 1-9, Submitted July 2014; Revised Jan. 12, 2015; Accepted Feb. 20, 2015; www.ijera.com.

[7] Dr. N. Mukhopadhyay-Theoretical Convective Heat Transfer Model Development of Cold Storage Using Taguchi Analysis.IJERAISSN : 2248-9622, Vol. 5, Issue 1, ( Part -6) January 2015, pp.13-17

[8] Dr. N.Mukhopadhyay-Theoretical Convective Heat Transfer Model 
Development of Cold Storage Using TaguchiAnalysis.ISSN:2248-9622,

Vol.5,Issue 1,(part-6)January2015;

www.ijera.com.

[9] The effect of fin spacing and material on the performance of a heat sink with circular pin fins Department of Mechanical Engineering, Indian Institute of Technology Guwahati, Guwahati, Assam, India

[10] Theoretical Convective Heat Transfer Model Developement of Cold Storage Using Taguchi Analysis. Dr.N.Mukhopadhyay , Suman Debnath; www.ijera.com.

[11] B.Kundu- international communications in heat and mass transfer, 2002.(An analytica study of the effect of dehumidification of air on the performance and optimization of straight tapered fins.

[12] The effect of fin spacing and material on the performance of a heat sink with circular pin fins Department of Mechanical Engineering, Indian Institute of Technology Guwahati, Guwahati, Assam, India

[13] ASHRAE Handbook of Fundamentals, 1993.

[14] Process heat transfer by DONAL Q. KERN (M $\left.\mathrm{M}_{\mathrm{C}} \mathrm{GRAW}-\mathrm{HILL}\right)$.

[15] Heat and Mass Transfer; Yunus A. Cengel; Third Edition.

[16] Fundamentals of Signal-to-Noise Ratio (SNR) by Christopher M Collins

[17] Signal to Noise Ratio for Quality Evaluation by Genechi Taguchi

[18] Condenser and Evaporator-Version I ME IIT Kharagpur Lesson 22

[19] www.engineeringtoolbox.com 